
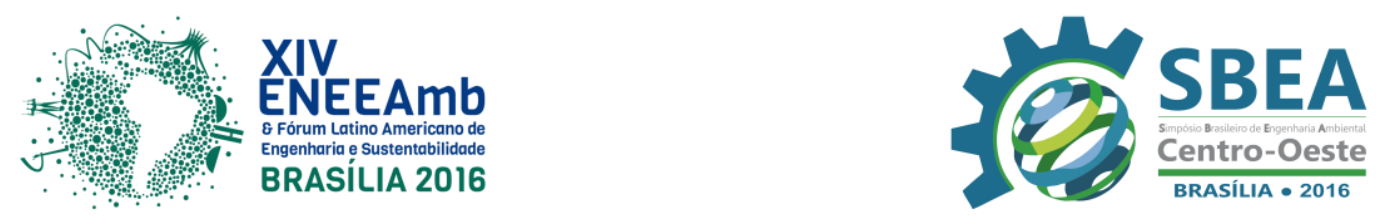

ENERGIAS RENOVÁVEIS

\title{
A EÓLICO-ELETRICIDADE COMO ALTERNATIVA ENERGÉTICA SUSTENTÁVEL NA BAHIA
}

\author{
Isabela Santos Aragão - aragaobela@eambjr.com.br \\ Instituto Federal de Educação, Ciência e Tecnologia da Bahia. \\ Roberta Rodrigues de Albuquerque - robertaalb14@gmail.com \\ Instituto Federal de Educação, Ciência e Tecnologia da Bahia. \\ Maria Clara Gonçalves Santos - goncalvesantos.clara@ hotmail.com \\ Instituto Federal de Educação, Ciência e Tecnologia da Bahia.
}

\begin{abstract}
Resumo: Os países desenvolvidos tem realizado grandes investimentos em relação à diversificação de suas matrizes energéticas, não só pelas demandas crescentes de energia, como também pela busca de fontes renováveis, limpas e econômicas. A energia eólica vem como uma opção de fonte promissora, especialmente por ser abundante, renovável, limpa e não emissora de gases causadores do efeito estufa. O Brasil destaca-se no cenário mundial por possuir um imenso potencial eólico ainda não explorado e, somado a tal fato, ressalta-se também o progressivo declínio nos custos de implantação de unidades geradoras eólicas. No estado da Bahia, uma nova alternativa de matriz energética começa a ser explorada, a eólica, tal desenvolvimento ocorre devido a sua localização estratégica numa região de transição entre regimes distintos de ventos. O aumento da demanda energética e desenvolvimento tecnológico, a expansão da própria infraestrutura, implantação de grandes plantas industriais, além de ser economicamente favorável são agentes que estimulam os projetos de energia eólica para o estado. O presente artigo discute o potencial eólico-energético do Estado da Bahia, avaliando como este tipo de energia pode ser economicamente sustentável na geração de eletricidade, e discute sobre os pontos da região para possíveis instalações de parques eólicos.
\end{abstract}

Palavras-chave: Sustentabilidade, potencial eólico, energia renovável, Fontes limpas.

\section{INTRODUÇÃO E OBJETIVOS}

Segundo a Secretaria da Indústria, Comércio e Mineração da Bahia(2014), a busca por fontes alternativas de energia está entre as maiores preocupações do mundo contemporâneo. $\mathrm{O}$ alto custo da produção de energia, a demanda sempre crescente e os desafios do desenvolvimento com sustentabilidade geraram um grande interesse dos países em desenvolver formas e equipamentos para produção de eletricidade que contribuam para a redução da dependência do uso de combustíveis fósseis, e para busca por alternativas de energia limpa, como exemplos, a energia solar e a eólica. 

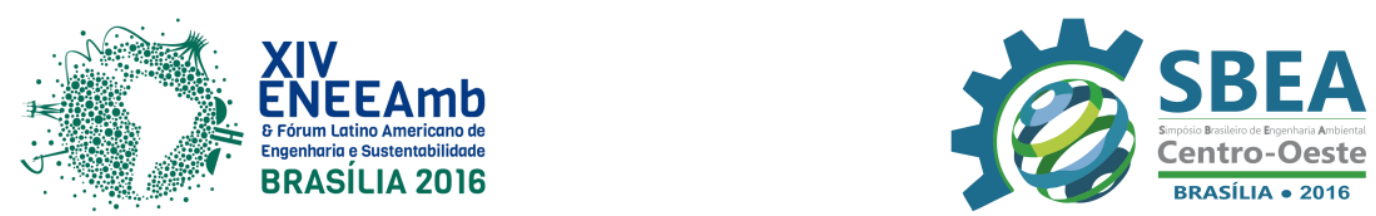

A energia eólica é utilizada desde a antiguidade para mover os barcos a vela, mover moinhos entre outras atividades. Recentemente passou-se a utilizar a energia eólica para mover turbinas instaladas em locais com superabundância de ventos, afim de produzir energia. Essas turbinas apresentam geralmente a forma de um cata-vento, e são agrupadas em parques eólicos, que são um agrupamento de várias turbinas necessárias para que a produção de energia se torne economicamente viável.

A energia eólica é considerada uma das mais promissoras fontes de energia renováveis, apresentando também uma grande vantagem, causar baixos impactos ao meio ambiente. Além disso, é distribuída globalmente, utilizada para substituir fontes de combustíveis fósseis, auxiliando na redução das emissões atmosféricas.

As turbinas eólicas podem ser utilizadas em conexões interligadas a rede elétrica ou em lugares isolados. A sua utilização para a geração de eletricidade, em escala comercial, teve início há pouco mais de 30 anos e evoluiu rapidamente da prancheta para produtos de alta tecnologia.

O Brasil tem um dos maiores potenciais eólicos do planeta: mais de $71 \mathrm{mil} \mathrm{km}^{2}$ do território nacional conta com velocidades de vento superiores a $7 \mathrm{~m} / \mathrm{s}$, principalmente nos estados da região Nordeste do país. O potencial eólico do Brasil chega a 143 mil MW, 11 vezes maior que a potência instalada da Usina de Itaipu. Essa estimativa foi realizada em 2001, com medições a 50m de altura. Atualmente, os aerogeradores alcançam, em alguns casos, altura superior à 100m, o que indica que o potencial a ser aproveitado é bem maior.

A Bahia apresenta um significativo potencial de energia eólica, estimado em $14,5 \mathrm{GW}$ para uma altura de $70 \mathrm{~m}$ - o que representa $10,1 \%$ do potencial nacional e $19,3 \%$ do potencial da região Nordeste. Diferente dos outros estados da região, que tem maior incidência de ventos no litoral, a Bahia concentra seu potencial eólico no interior, ao longo de toda margem direita do Rio São Francisco, desde a Serra do Espinhaço até Juazeiro, atravessando a Chapada Diamantina e o vale são-franciscano.

Atualmente, a Bahia é o segundo maior estado em potência contratada nos leilões de energia eólica. Quando os 57 projetos previstos para se instalar no estado estiverem funcionando, vão acrescentar aproximadamente $1.560 \mathrm{MW}$ à rede elétrica (Secretaria da Indústria, Comércio e Mineração da Bahia, 2014).

O presente artigo teve como finalidade evidenciar o potencial eólico do Estado da Bahia indicando alguns pontos estratégicos para implantação de parques eólicos apontando as maiores dificuldades e também benefícios.

\section{METODOLOGIA}

Este trabalho utilizou metodologias exploratórias para obtenção de dados e consistiu em uma análise qualitativa e detalhada sobre a Energia Eólica como alternativa sustentável na Bahia.

Teve como principais bases teóricas o Atlas do Potencial Eólico Brasileiro e o Atlas do Potencial Eólico do Estado da Bahia. Também utilizou-se como base de dados a biblioteca eletrônica on-line SciELO, a qual dispõe artigos e periódicos nacionais e internacionais de diferentes áreas.

Dando continuidade na pesquisa com o auxílio da biblioteca SciELO, realizou-se buscas com o uso de palavras-chaves que foram escolhidas devido às relações diretas com o 

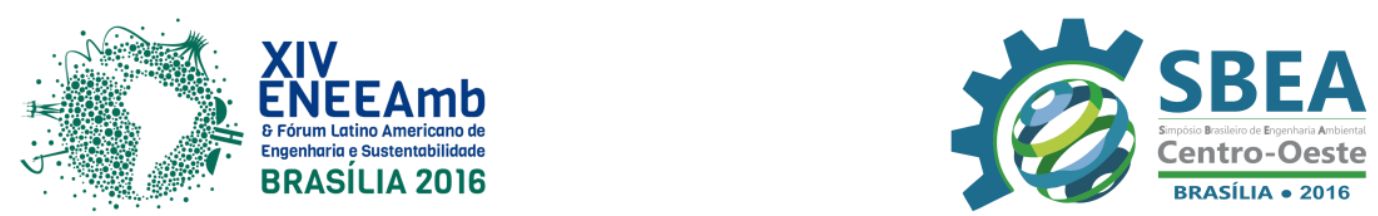

objeto de estudo. Os resultados encontrados a partir das buscas passaram por uma triagem para identificar os artigos ou periódicos que se referiam à energia eólica em seu contexto.

\section{RESULTADOS E DISCUSSÕES}

O nordeste brasileiro reúne condições favoráveis para a produção de energia eólica. Tendo como estado de maior destaque o da Bahia, devido a extensão territorial que é um fator determinante para a implantação de parques eólicos, bem como a condição dos ventos que varia pouco, e apresentam valores elevados de velocidades médias o que permite o uso de mais de 50\% da capacidade dos aerogeradores. A nível de comparação, a Alemanha, que é o terceiro maior produtor de energia eólica do mundo aproveita somente $20 \%$ da capacidade do equipamento. A figura 1 mostra um mapa do potencial baiano, e leva em consideração a velocidade média anual dos ventos para areogeradores a 70 metros de altura.

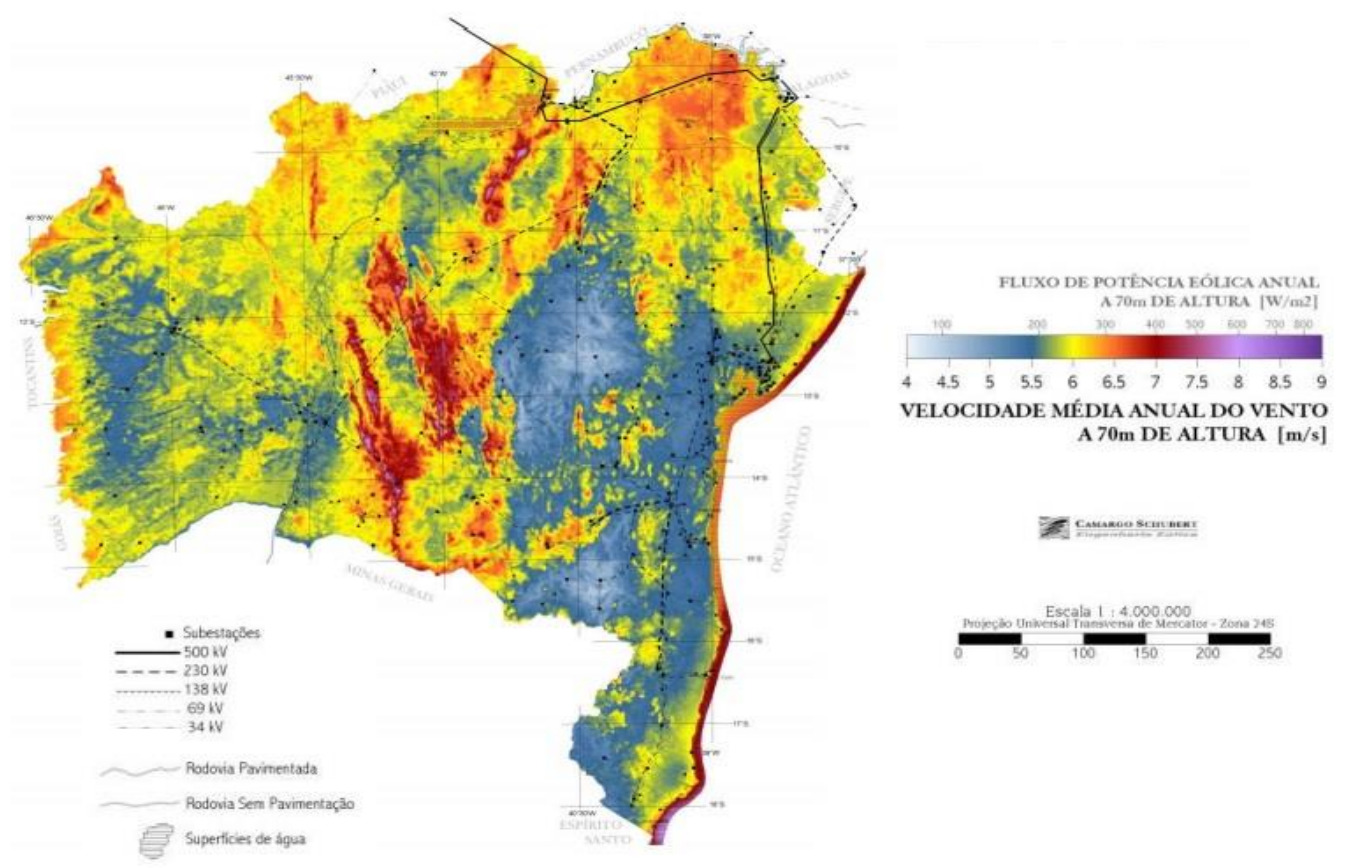

Figura 1- Mapa do potencial eólico baiano para aerogeradores a 70m de altura. Fonte: Atlas Eólico da Bahia

Atualmente, o estado conta com um dos maiores parques eólicos da América Latina, instalado nos municípios de Caetité, Guanambi, Igaporã e Sobradinho. A Bahia também apresenta uma vantagem em relação aos outros estados nordestinos, pois apresenta uma maior proximidade do Sudeste, que corresponde a região que mais consome energia, logo compradora em potencial, essa proximidade é importante para a logística e reduz os custos de transmissão.

De acordo com o Atlas do Potencial Eólico da Bahia, os parques aerogeradores devem ser instalados em locais onde não causem impactos ambientais negativos. Desse modo, exclui reservas indígenas, áreas de proteção ambiental, áreas urbanas, entre outros. 

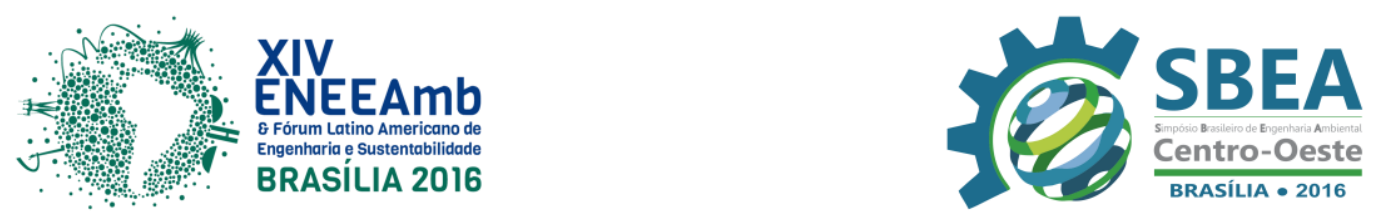

Segundo Domingos Zaparolli, as melhores regiões para se investir em parques eólicos, diferentemente de outros estados não se concentram no litoral, e sim em cidades localizadas no interior e em sua maioria banhadas pelas águas do Rio São Francisco. A tabela 1 abaixo mostra as principais regiões para a implantação de parques eólicos e sua capacidade eólica estimada em gigawatts.

Tabela 1 - Principais regiões para implantação de parques eólicos

\begin{tabular}{|l|l|}
\hline Região & Capacidade Estimada \\
\hline Sobradinho, Sento Sé e Casa Nova & $6,2 \mathrm{GW}$ \\
\hline Região das serras Azul e Açuruá & $7,6 \mathrm{GW}$ \\
\hline Morro do Chapéu & $10 \mathrm{GW}$ \\
\hline Serra do Estreito & $2,4 \mathrm{GW}$ \\
\hline Serra do Espinhaço & $5,6 \mathrm{GW}$ \\
\hline $\begin{array}{l}\text { Novo Horizonte, Piatã, Ibitiara e Brotas de } \\
\text { Macaúbas }\end{array}$ & $3,5 \mathrm{GW}$ \\
\hline
\end{tabular}

Fonte: Revista Bahiaciência (2014)

O fator que mais restringe a implantação de empreendimentos eólicos na Bahia tem sido a escassez de dados seguros e coerentes. A disponibilidade desses dados é importante, pois possibilita explorar o recurso eólico abundante e renovável de forma significativa e segura para o empreendedor e para a população.

\section{CONSIDERAÇÕES FINAIS}

O presente estudo identificou a relevância da energia eólica como uma fonte promissora de energia limpa e renovável diante do atual desafio, que é aliar com a demanda energética à sustentabilidade. Diante do exposto, estima-se que o estado da Bahia pode contribuir de forma significativa para uma modificação da matriz energética brasileira, visto que o estado apresenta uma das melhores condições geográficas e ambientais para empreendimentos de energia eólica.

$\mathrm{O}$ território baiano possui particularidades que o torna ideal para o investimento em energia eólica, além da expressiva área territorial conta também com áreas planas em altas atitudes e relevo com rugosidade bastante favorável, as vegetações das serras e chapadas geralmente crescem inclinadas pela ação contínua dos ventos, tais características servem como indicadores biológicos de locais que apresentam melhores potenciais eólicos.

A partir do estudo evidenciou-se que apesar da Bahia ter um potencial eólicoenergético alto ainda se faz necessário investimentos em pesquisas e estudos a fim de se obter dados expressivos e confiáveis para se desenvolver tecnologias sustentáveis capazes de aproveitar ao máximo esta fonte energética. 


\section{REFERÊNCIAS E CITAÇÕES}

ATLAS EÓLICO DA BAHIA. Disponível em: www.cresesb.cepel.br/publicacoes/download/atlas_eolico/atlas_eolico_BA.pdf. Acesso em: 01 maio 2016.

BAHIA (Estado). Secretaria da Indústria, Comércio e Mineração. Diretoria de Desenvolvimento e Relações Internacionais e Superintendência de Desenvolvimento Econômico. Energia Eólica. Bahia, 3 p.

ZAPAROLLI, D. A força dos ventos. Revista Bahiaciência, Bahia, v.1, n.1, p .35-39, 2014. 